\title{
Potential Impact of Biostimulator NeOsol and Three Different Manure Types on Physical Soil Properties and Crop Status in Heavy Soils Conditions
}

\author{
Václav Novák ${ }^{1}$, Petr Šařec ${ }^{1, * \mathbb{D}}$, Kateřina Kř́žová ${ }^{1,2}$, Petr Novák ${ }^{3}$ and Oldřich Látal ${ }^{4}$ (D) \\ 1 Department of Machinery Utilization, Faculty of Engineering, Czech University of Life Sciences Prague, \\ 16500 Prague, Czech Republic; novakvaclav@tf.czu.cz (V.N.); krizovak@tf.czu.cz (K.K.) \\ 2 Division of Crop Protection and Plant Health, Crop Research Institute, 16106 Prague, Czech Republic \\ 3 Department of Agricultural Machines, Faculty of Engineering, Czech University of Life Sciences Prague, \\ 16500 Prague, Czech Republic; novakpetr@tf.czu.cz \\ 4 Department of Agrochemistry, Soil Science, Microbiology and Plant Nutrition, Faculty of AgriSciences, \\ Mendel University in Brno, 61300 Brno, Czech Republic; oldrich.latal@mendelu.cz \\ * Correspondence: psarec@tf.czu.cz
}

\section{check for}

updates

Citation: Novák, V.; Šařec, P.;

Kř́žová, K.; Novák, P.; Látal, O.

Potential Impact of Biostimulator NeOsol and Three Different Manure Types on Physical Soil Properties and Crop Status in Heavy Soils Conditions. Sustainability 2022, 14, 438. https://doi.org/10.3390/ su14010438

Academic Editor: José Manuel Mirás-Avalos

Received: 2 December 2021 Accepted: 28 December 2021 Published: 31 December 2021

Publisher's Note: MDPI stays neutral with regard to jurisdictional claims in published maps and institutional affiliations.

Copyright: (C) 2021 by the authors. Licensee MDPI, Basel, Switzerland. This article is an open access article distributed under the terms and conditions of the Creative Commons Attribution (CC BY) license (https:// creativecommons.org/licenses/by/ $4.0 /)$.

\begin{abstract}
This study was conducted to understand the long-term influence of biostimulator NeOsol in combination with different manure types on soil's physical properties and crop status. NeOsol is a soil biostimulator that should stimulate the biological reactions of the soil profile and improve the soil's physical and chemical properties. A six-year experiment was conducted with eight treatments: NPK, cattle manure, pig manure, poultry manure, and the same four treatments with the NeOsol added on top. The in situ sampling of soil properties provided data on unit draft (UD), bulk density (BD), and saturated hydraulic conductivity (SHC). Furthermore, remotely sensed data were analyzed to describe crop status via three selected vegetation indices (VI), and crop yields were assessed last. The variants treated with NeOsol demonstrated decreases in UD over time; BD, SHC, and VI did not significantly change. The impact on yield was significant and increased over time. When comparing the variants with manure application to those without one, the cattle manure led to significantly higher SHC; the pig manure led to significantly lower UD and BD but significantly higher SHC and yield; and the poultry manure led to significantly lower UD and BD but higher yield.
\end{abstract}

Keywords: bulk density; unit draft; saturated hydraulic conductivity; yield; Sentinel-2

\section{Introduction}

The growing population and the impacts of climate change are the major drivers of a significant revolution in current agriculture. Today, farmers around the globe are under substantial pressure to ensure still-higher yields in a limited area. In doing so, they must adjust their common management to actual environmental policies. Although the impacts of changing climate vary among regions and by crop, it is clear that responsible strategies must be adopted on a global scale [1] Research-based technologies began to be implemented in the 1950s [2] Collecting, processing, and transferring data into practice are some of the cornerstones of precision agriculture, one of the staple concepts of the ongoing Agriculture 4.0 [3] Properly interpreted results then enable practitioners to (a) increase productivity, (b) reasonably allocate sources, (c) adapt agricultural management, and (d) avoid food waste [4] Along with the rapid development in technology over recent decades, significant efforts have been undertaken to design and apply technologies helping to fight emerging food production issues [5].

Soil fertility is a major factor for sustainable agriculture [6]. Soil properties, including infiltration and soil structure stability may be improved with manure application. The method, rate, and timing of manure application should be considered to reduce environmental impacts, e.g., soil erosion [7]. Soil erosion by water is an outcome of two main 
processes: firstly, the detachment of soil particles from the soil surface by raindrop impact, and secondly, the transport of the detached particles by raindrop splash or surface runoff. Hence, the structure stability of the soils affects the rate of soil erosion. Management practices [8] used to control runoff include contouring, strip cropping, conservation tillage, terraces, and buffer strips. More than one runoff-control practice may be necessary for protection in areas with high runoff potential. Current intensive agricultural management often fatigues the soil to an extreme extent in some regions, so fertility has to be restored by a fertilizer supply [9]. Generally, organic fertilizers act as natural products while manufactured mineral fertilizers mostly consist of ideal combinations of NPK nutrients. Although mineral fertilizers appear to be an easy solution to soil fertility issues, it concurrently has many other negative impacts on the surrounding environment as a whole. Thus, properly managed organic fertilizers are the preferable option, since it is commonly known that they positively influence both chemical and physical soil properties [10]. Nevertheless, the amount of produced organic fertilizers has decreased in Europe over recent decades as animal husbandry (such as cattle and pigs) has been significantly reduced [11]. Therefore, new approaches are being researched and tested to exploit the positive features of organic fertilizers as much as possible. NeOsol (previously PRP SOL) is manufactured by Olmix Group (France) as a soil microbial biomass activator. When applied to a soil profile, it is supposed to stimulate soil biological activity and hence promote hummus synthesis. Various studies have already been conducted to describe NeOsol's actual impact on (a) soil properties, (b) plant status, (c) crop yields, and (d) compost properties. According Spychalski et al. [12], PRP SOL significantly influenced the chemical properties of soil by increasing $\mathrm{pH}$ and available form of magnesium, as well as by decreasing available forms of potassium. Enhanced water and nutrient uptake [13], favorable effects on soil compaction and the moisture status of the top layer [14], and reductions in the force required by soil tillage [15] were observed. Furthermore, beneficial impacts on the enzymatic activity of sand and clay soils were described by Bielińska et al. [16]. Naturally, enhanced soil properties directly impact crop growth. This was the subject of a study by Borowiak et al. [17], where PRP SOL had a positive effect on the photosynthesis rate and plant growth of spring barley and maize. PRP SOL was found to significantly enhance chlorophyll content in the leaf blades of ryegrass [18]. Various studies have also described higher yields of soybean [19], potatoes [20], and the dry matter of calendula [21] with the use of PRP SOL. Porro and Pedò [22] found that grape vines on vineyards treated with PRP SOL were in better physiological and eco-physiological condition than controls, and the taste of the final products was fruitier and more floral. The biostimulative potential of the PRP SOL was studied in combination with municipal compost, where the total contents of nickel, manganese, lead, and their soluble forms in soil were observed [23]. Furthermore, the application of compost in combination with PRP SOL had a significantly positive impact on wheat grain yield [24].

Although the above-mentioned studies addressed the topic of the biostimulator $\mathrm{NeOsol}$, this study was aimed at verifying the effectiveness of this soil agent and its effect on enhancing the outcome of the three types of manure in a six-year experiment in real agricultural conditions. The hypotheses to be verified are as follows: the use of this soil agent would lead to (a) reductions in implement unit draft and bulk density, (b) increase in saturated hydraulic conductivity, (c) enhancement of crop growth, and (d) increase in crop yield.

\section{Materials and Methods}

\subsection{Biostimulator $\mathrm{NeOsol}$}

$\mathrm{NeOsol} \mathrm{is} \mathrm{manufactured} \mathrm{by} \mathrm{Olmix} \mathrm{Group} \mathrm{(Bréhan,} \mathrm{France)} \mathrm{as} \mathrm{a} \mathrm{granular} \mathrm{biostimulator}$ of vital soil functions. This soil agent uses the patented technology MIP (Mineral Inducer Process). It exploits the bioactive properties of minerals and specific trace elements to stimulate the biological reactions within the soil profile. More specifically, it uses iron, manganese, copper, and boron to stimulate enzymatic reactions involved in the transformation of raw organic matter, especially humification ( $\alpha$-glucosidase, $\beta$-glucosidase, etc.). In 
addition to MIP technology, NeOsol also uses SEAweed DRY algae extracts, which are rich in nutrients, for soil biota stimulation.

This biostimulator is declared to contain $28.0 \% w / w$ of $\mathrm{CaO}, 15.9 \% w / w$ of $\mathrm{MgO}$, and $98.9 \% w / w$ of dry matter, from which the combustible substances create $7 \% \mathrm{w} / \mathrm{DMw}$. The $\mathrm{pH}$ varies from 8 to 10 , i.e., it is strongly alkaline.

The recommended dose ranges between 100 and $200 \mathrm{~kg} \mathrm{ha}^{-1}$, depending on crop and local soil conditions. The application is conducted after harvest in the same manner as granular mineral fertilizers, i.e., it is sprinkled on a soil's surface.

\subsection{Site and Crop Management}

A six-year study was undertaken within the experimental field near the town of Městec Králové in Central Bohemia of the Czech Republic $\left(50^{\circ} 14.256^{\prime}\right.$ N, $15^{\circ} 20.705^{\prime}$ E, 235 masl.). In terms of soil conditions, initial sampling was conducted at the beginning of the experiment in 2014 after the harvest of barley, and the characteristics are given in Table 1. The experiment was based on heavy soil (Gleyic Phaeozem), often referred to as difficult in terms of soil tillage management. In terms of texture, the soil fell into the clay category according to the USDA texture triangle.

Table 1. Analysis of the chemical and physical composition of the soil conducted at the beginning of the experiment in 2014.

\begin{tabular}{cccc}
\hline & \multicolumn{2}{c}{ Soil Profile Depth $\mathbf{( m )}$} & Unit \\
& $\mathbf{0 . 0 0 - 0 . 3 0}$ & $\mathbf{0 . 3 0 - 0 . 6 0}$ & \\
\hline Clay $(<0.002 \mathrm{~mm})$ & 48 & 60 & $\% \mathrm{w} / \mathrm{w}$ \\
Silt $(0.002-0.05 \mathrm{~mm})$ & 32 & 39 & $\% \mathrm{w} / \mathrm{w}$ \\
Very fine sand $(0.05-0.10 \mathrm{~mm})$ & 2 & 1 & $\% \mathrm{w} / \mathrm{w}$ \\
Fine sand $(0.10-0.25 \mathrm{~mm})$ & 18 & 0 & $\mathrm{~g} \mathrm{~cm} \mathrm{c}^{-1}$ \\
Bulk density & 1.46 & 1.48 & $\% \mathrm{w} / \mathrm{w}$ \\
Porosity & 46.15 & 43.99 & $\mathrm{mmol} \mathrm{kg}$ \\
Hummus content & 3.89 & 1.44 & $\% \mathrm{v} / \mathrm{v}$ \\
Cation exchange capacity & 278 & 272 & \\
Volumetric moisture & 35.65 & 40.20 & \\
pH $(\mathrm{KCl})$ & 7.18 & 7.21 &
\end{tabular}

The experimental field was divided into smaller plots with a rectangular area of $45 \times 140 \mathrm{~m}(0.63 \mathrm{ha})$ per variant. These small plots were arranged with respect to the shape of the experimental field, and the headlands were left out. The characteristics of the treatments of particular variants with manure of different origin or with $\mathrm{NeOsol}$ are depicted in Table 2. Standard NPK mineral fertilizer was applied during vegetation to top up the nutrients contained in manure so that the recommended [25] full dose of nutrients for a specific crop grown was attained. Of course, the variant NPK, i.e., the control variant, was left without any additional treatment and the recommended full NPK dose including ground fertilization in autumn. This complex of treatments finally provided a set of eight variants, where all the subsequent samplings were undertaken.

The crop rotation system in the experimental field was carried out according to standard local practice. The agricultural business was located in a sugar beet production region with the crop rotation of cereals, corn, and either oilseed rape, or sugar beet. The latter two should not rotate in the same field. The standard crop rotation of the trial field included oilseed rape. The schedule of each field management practice during the experiment period is presented by Table 3. All types of manure were applied in fall using a manure spreader, while the $\mathrm{NeOsol}$ application proceeded immediately after harvest by a fertilizer spreader. 
Table 2. Treatment of individual variants during the experimental period (2014-2020).

\begin{tabular}{cccc}
\hline Variant & NPK & Treatment \\
Manure & NeOsol \\
\hline NPK & Yes-full rate & No & No \\
NPKSOL & Yes-full rate & No & Yes \\
catt & Yes-top-up rate & Yes-cattle & No \\
cattSOL & Yes-top-up rate & Yes-cattle & Yes \\
pig & Yes-top-up rate & Yes-pig & No \\
pigSOL & Yes-top-up rate & Yes-pig & Yes \\
pou & Yes-top-up rate & Yes-poultry & No \\
pouSOL & Yes-top-up rate & Yes-poultry & Yes
\end{tabular}

${ }^{1}$ NPK application rate was calculated to top up the nutrients contained in manure so that the recommended [25] full dose of nutrients was attained in $\mathrm{kg} \mathrm{ha}^{-1}$ : corn (N 185; P 30; K 190); winter wheat (N 180; P 35; K 95); spring barley (N 140; P 30; K 80).

Table 3. Crop rotation and agricultural management during the experimental period (2014-2020).

\begin{tabular}{|c|c|c|c|c|c|c|c|}
\hline Season & Sowing Date & Harvest Date & Crop & $\begin{array}{c}\text { NeOsol } \\
\left(\mathrm{kg} \mathrm{ha}^{-1}\right)\end{array}$ & $\begin{array}{l}\text { Cow Manure } \\
\left(\mathrm{t} \mathrm{ha} \mathbf{a}^{-1}\right)\end{array}$ & $\begin{array}{l}\text { Pig Manure } \\
\left.\text { (t ha } a^{-1}\right)\end{array}$ & $\begin{array}{l}\text { Poultry Manure } \\
\left.\text { (t ha }{ }^{-1}\right)\end{array}$ \\
\hline 2014 & - & - & Barley & 200 & 50 & 40 & 10 \\
\hline 2015 Term I & 14.4 .2015 & 27.8.2015 & Corn & 200 & - & - & - \\
\hline 2016 & 23.3.2016 & 5.8 .2016 & Spring barley & 200 & 50 & 20 & 8 \\
\hline 2017 Term II & 2.11.2016 & 4.8.2017 & Winter wheat & 150 & - & - & - \\
\hline 2018 & 10.4 .2018 & 3.8.2018 & Corn & 150 & - & - & - \\
\hline 2019 & 5.10 .2018 & 24.7.2019 & Winter wheat & 150 & 30 & 20 & 10 \\
\hline 2020 Term III & 15.10 .2019 & 30.7 .2020 & Winter wheat & 150 & - & - & - \\
\hline
\end{tabular}

\subsection{Data Acquisition and Processing}

Data assessment was performed for three terms selected to follow in the same interval after the manure application, i.e., in 2015 (Term I), 2017 (Term II), and 2020 (Term III). Hereby, the potential influence of uneven interval between the treatment and measurements was eliminated. The soil's physical properties were sampled by in situ measurements performed either in spring (bulk density and saturated hydraulic conductivity) or autumn (unit draft). To acquire data on unit draft (UD), a dynamometer with S-38/200 kN strain gauges (Lukas, Prague, the Czech Republic) was placed in a horizontal position between two tractors. Firstly, measurements were accomplished with the tillage implement at a working depth and a constant speed in order to measure the overall draft of the pulled tractor and the working implement. The working depth was verified by measurement after each pass. Secondly, the not-working implement was used to measure the rolling resistance and the force induced by the potential field gradient. These were deduced from the overall draft in order to calculate the implement draft. The direction of passes was also taken into account. With regard to common agricultural practices, measurements were made with different types of implements and at different depths of soil tillage. A Köckerling Vario 480 tine cultivator was operated at depths of $11 \mathrm{~cm}$ (2015-Term I) and $7 \mathrm{~cm}(2020-$ Term III). Furthermore, a Horsch Terrano 8 FG tine cultivator was operated at $15 \mathrm{~cm}$ (2017-Term II). There were several passes done with each variant and the non-working and working implements, and GPS data were recorded by Trimble Business Center 2.70 (Trimble, Sunnyvale, California, USA). Simultaneously, raw UD data were collected using the NI CompactRIO system (National Instruments Corporation, Austin, Texas, USA). The sampling frequency for both GPS and UD was $0.1 \mathrm{~s}$.

Furthermore, bulk density (BD) was determined via soil samples obtained using a soil sample ring kit (Eijkelkamp, Giesbeek Netherlands). The volume of each ring was $100 \mathrm{~cm}^{3}$, and sampling was performed in three repetitions per variant. Further BD soil sample processing involved analysis in the laboratories of the Engineering Faculty of the Czech University of Life Sciences in Prague according to the national standard CSN EN ISO 17892-2. 
Saturated hydraulic conductivity (SHC) was measured according to the simplified Falling-head method of Bagarello et al. [26]. It uses circular infiltrometers (in this case, $0.15 \mathrm{~m}$ diameter) and a known amount of water $(0.5 \mathrm{l})$, which is subsequently poured on the soil surface in the area of the infiltrometer. Volumetric soil moisture was measured with a Theta Probe (Delta-T Devices, Ltd., UK) before and after water application. The time of water infiltration was measured for the later calculation of the final SHC value $K_{f s}$ (Equation (1)).

$$
K_{f s}=\frac{(\Delta \theta)}{(1-\Delta \theta) t_{\alpha}}\left\lceil\frac{D}{\Delta \theta}-\frac{\left(D+\frac{1}{\alpha^{*}}\right)}{(1-\Delta \theta)} \ln \left(1+\frac{(1-\Delta \theta) D}{(\Delta \theta)\left(D+\frac{1}{\alpha^{*}}\right)}\right)\right]
$$

here: $\Delta \theta=$ difference between initial soil moisture content and saturated soil moisture content; $D=$ the ratio of $\mathrm{V}$ (volume of water) and $A$ (area of a cylinder), which is the water level corresponding to the water volume; $t_{\alpha}=$ infiltration time; and $\alpha=$ constant according to Elrick et al. [27].

Potential differences in the soil's physical properties between investigated treatments were determined through one-way (factor: term) or factorial (factors: term; manure type; NeOsol treatment) analyses of variance (ANOVA) and Tukey HSD post-hoc tests.

\subsection{Crop Status}

A secondary effect of the investigated treatments on crops within selected variants was further determined. For this purpose, remotely sensed data were utilized because they result from a simple and widely used non-destructive method used to acquire spatial data of crop status.

The European Space Agency (ESA) provides freely available remotely sensed imagery taken by the constellation of Sentinel satellites. In this case, cloud-free multispectral data of the Sentinel-2 were utilized. Basic vegetation indices, namely the Normalized Difference Vegetation Index (NDVI) as a basic indicator of plant health and greenness [28], the Normalized Difference Water Index (NDWI) that provides information on water contents in plant tissues [29], and the Leaf Area Index (LAI) that describes the robustness of vegetation canopy [30], were calculated. This set of indicators complexly describes a canopy in terms of nutrient and water saturation. Since the Sentinel-2 data were not yet available in 2015 and 2016, the above-mentioned indices were calculated only for the following cropping seasons: 2017, 2018, 2019, and 2020.

The whole process of indices calculation was carried out in the Google Earth Engine (GEE), as it provides a convenient online environment where every step is controlled by JavaScript code. This saves a user from time-consuming, one-by-one image processing and ensures the repeatability of the same processing steps for every image in a collection. Using GEE, pre-processed and ready-to-use imagery does not have to be downloaded to a local computer because they are directly processed on the server. For the purpose of this study, a zonal statistics summary of three vegetation indices was exported in a text file and further processed in RStudio 1.4.1717, with $\mathrm{R}$ version 4.1.0 [31]. Potential differences in crop performance between investigated treatments were determined through analysis of variance (ANOVA) with the random effect of the image acquisition date to minimize the influence of varying index values through the cropping season.

Finally, crop yield was recorded using a combine harvester and a trailer positioned on a DINI ARGEO WWSB 16t portable static axle scale (DINI ARGEO S.r.l., Modena, Italy). The grain yield was weighed after each of set of three passes of the combine harvester per variant.

\section{Results}

\subsection{Unit Draft}

UD results are given in Figure 1, which also shows the multiple comparison analysis results based on Tukey's HSD test. The differences among investigated seasons were highly 
influenced by varying soil moisture during soil tillage, the type of the tillage implement used, and the depth of tillage. Therefore, comparisons of variants' UD were performed separately according to the particular terms by the one-way ANOVA. Statistically significant differences were detected for both pig manure variants, i.e., pig and pigSOL. Compared to NPK, NPKSOL, catt, and cattSOL, the pig manure variants attained considerably lower UD at Terms II and III. Pure pig manure variant (pig) values significantly differed from those obtained by NPK, NPKSOL, and catt at Term I. Otherwise, no notable differences were found. In the case of pigSOL, there was a gradual reduction in UD (relative to the NPK variant), overall reaching more than $10 \%$. This decrease could result in fuel savings of about $1 \mathrm{~L} \mathrm{ha}^{-1}$ (assuming an average power delivery efficiency of around $50 \%$ and the fuel requirements of tillage operations at a level of $20 \mathrm{~L} \mathrm{ha}^{-1}$ ).

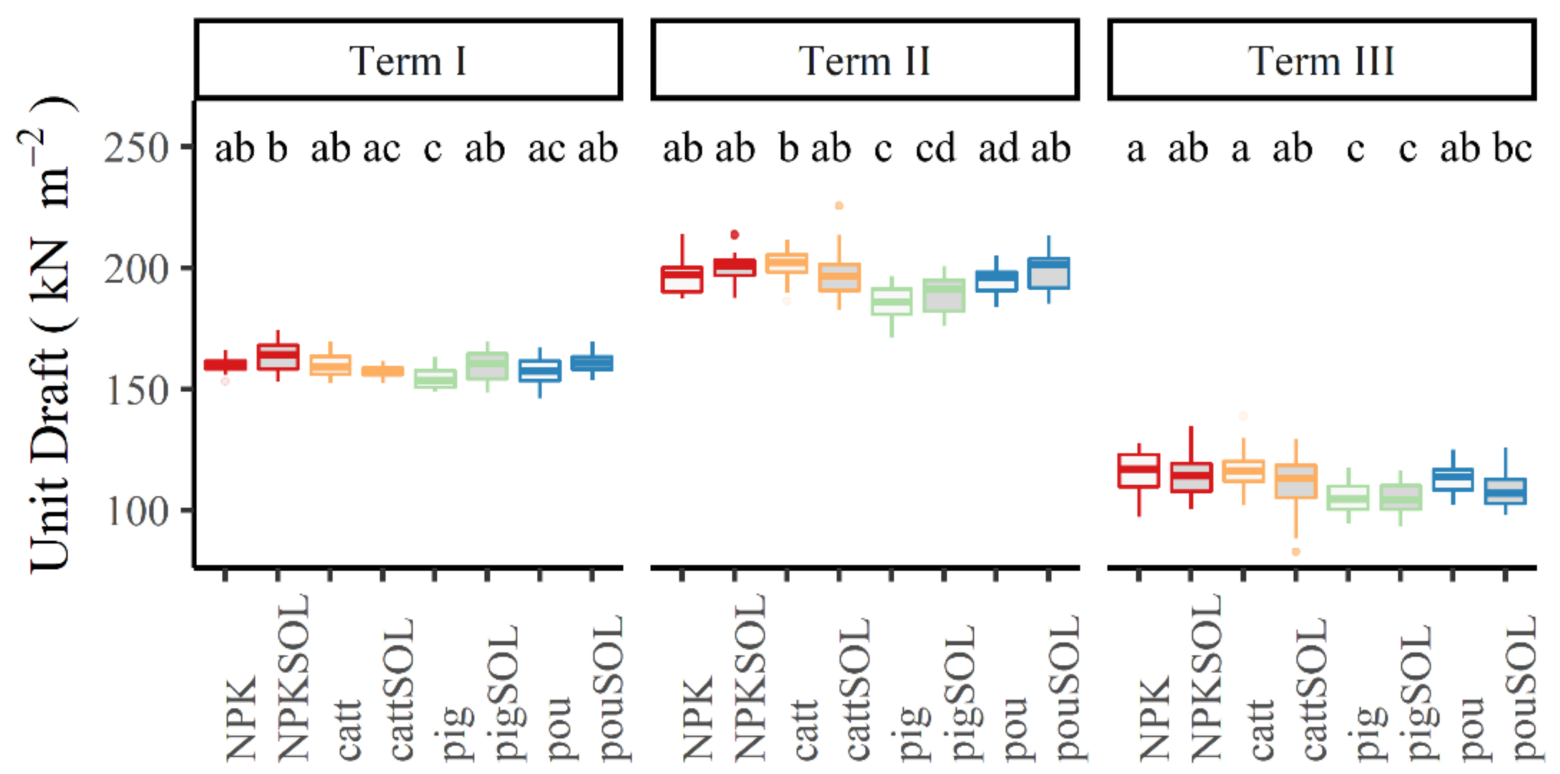

Figure 1. Unit draft within variants during the three investigated seasons. Error bars indicate the standard deviation, and letters represent multiple comparisons according to the results of Tukey's HSD test.

Additionally, the factorial (manure type; NeOsol treatment) ANOVA was employed separately for each of the terms. Concerning NeOsol treatment, Terms I and III presented significantly different results. Though variants treated with NeOsol attained higher UD values at Term I, the values become significantly lower at Term III. This fact suggests the favorable influence of the NeOsol activator on UD over a prolonged period of time. Regarding manure type, Term I presented significantly better (i.e., lower) UD values for the variants where cattle and particularly pig manure had been applied compared to the variants without any manure. At Term II, only both pig manure variants presented significantly lower UD values compared to all the other variants. The same outcome regarding the pig manure variants was present at Term III. Moreover, both variants with poultry manure showed significant and favorable differences compared to the variants without manure application.

\subsection{Bulk Density}

Figure 2 shows the results of soil bulk density analysis after calculating the final values. In general, BD is a relatively constant indicator that has a key effect on, for example, soil infiltration. At Term I, relatively homogeneous values could be observed, though they changed during the following years. In this regard, the overall difference between Term I and II was found to be statistically significant. A degressive reduction in BD could be observed, particularly with the application of poultry manure and pigSOL. The importance 
of organic matter in soil is reflected in the highest BD values of variants without any type of manure supply, i.e., NPK and NPKSOL. Furthermore, the NPKSOL variant demonstrated a gradual increase in values during the monitored periods. The pig variant always presented higher BD values than the pigSOL variant. Applying the factorial (term; manure type; NeOsol treatment) analysis of variance though the factor of NeOsol, i.e., regardless of manure type and term, demonstrated no significant differences. Concerning manure type, pig and poultry showed significantly lower BD values than variants where no manure was applied, with the poultry manure's BD values significantly differing compared to the cattle manure. Regarding individual terms, Term II provided significant decreases in BD compared to Term I.

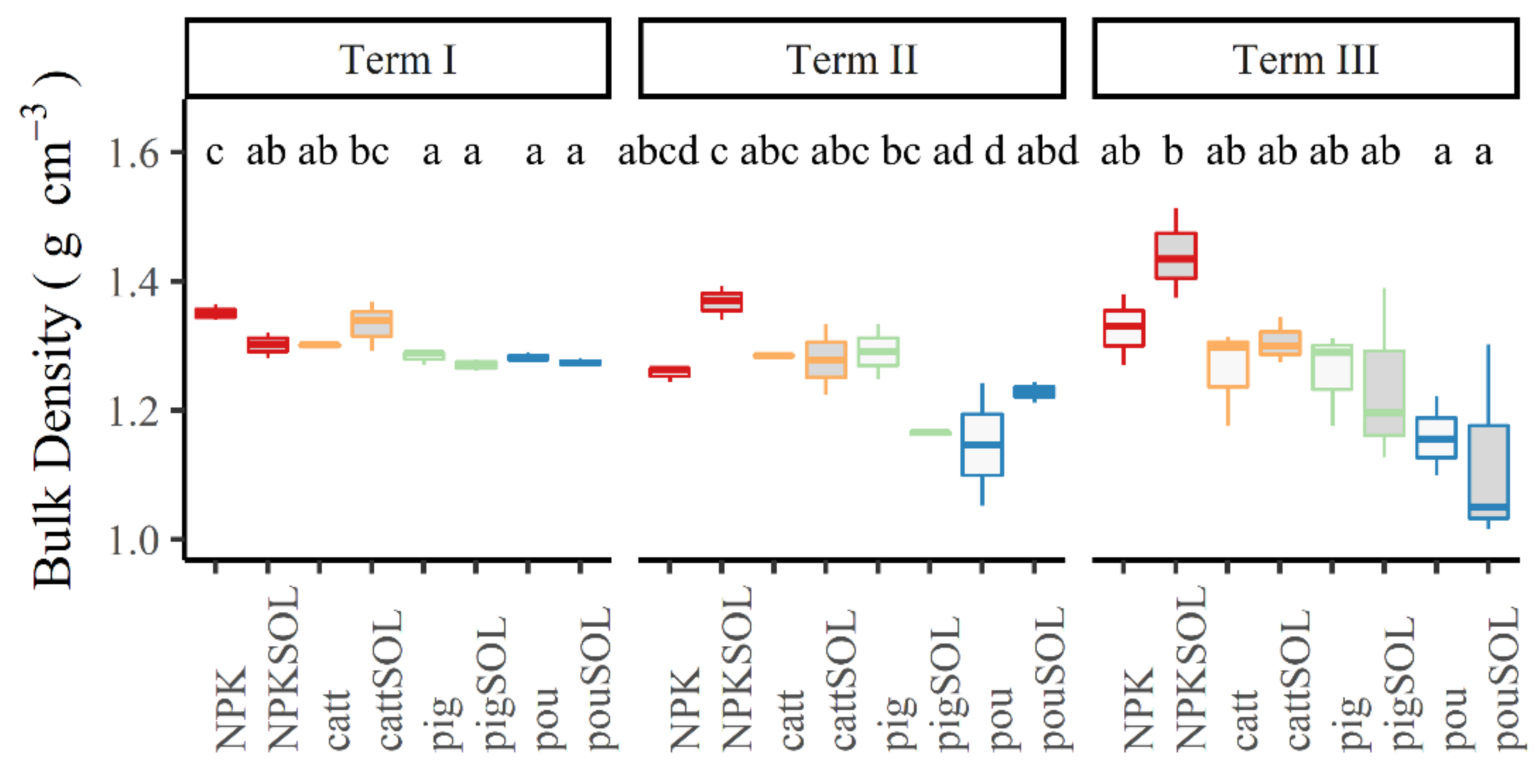

Figure 2. Bulk density within variants during the three investigated seasons. Error bars indicate the standard deviation, and letters represent multiple comparisons according to the results of Tukey's HSD test.

\subsection{Saturated Hydraulic Conductivity}

SHC results are presented in Figure 3. The values significantly differed among the terms, since the SHC was strongly influenced by the condition of the upper layer of the soil. Within the factorial (term; manure type; NeOsol treatment) analysis of variance, no significantly different values could be observed over the trial period between the variants, including those with/without the NeOsol biostimulator, although certain trends could be observed regarding the type of manure. The long-term use of pig manure and (particularly) cattle manure led to significantly improved SFH values compared to the variants without manure treatment. The SHC of both variants with cattle manure significantly surpassed the SHC values of variants with poultry manure. An adverse trend could be observed for the NPKSOL variant, where there was a constant decrease in SHC compared to the NPK variant. The addition of SOL to poultry manure increased the SHC value at each term, but this difference was not statistically significant. 


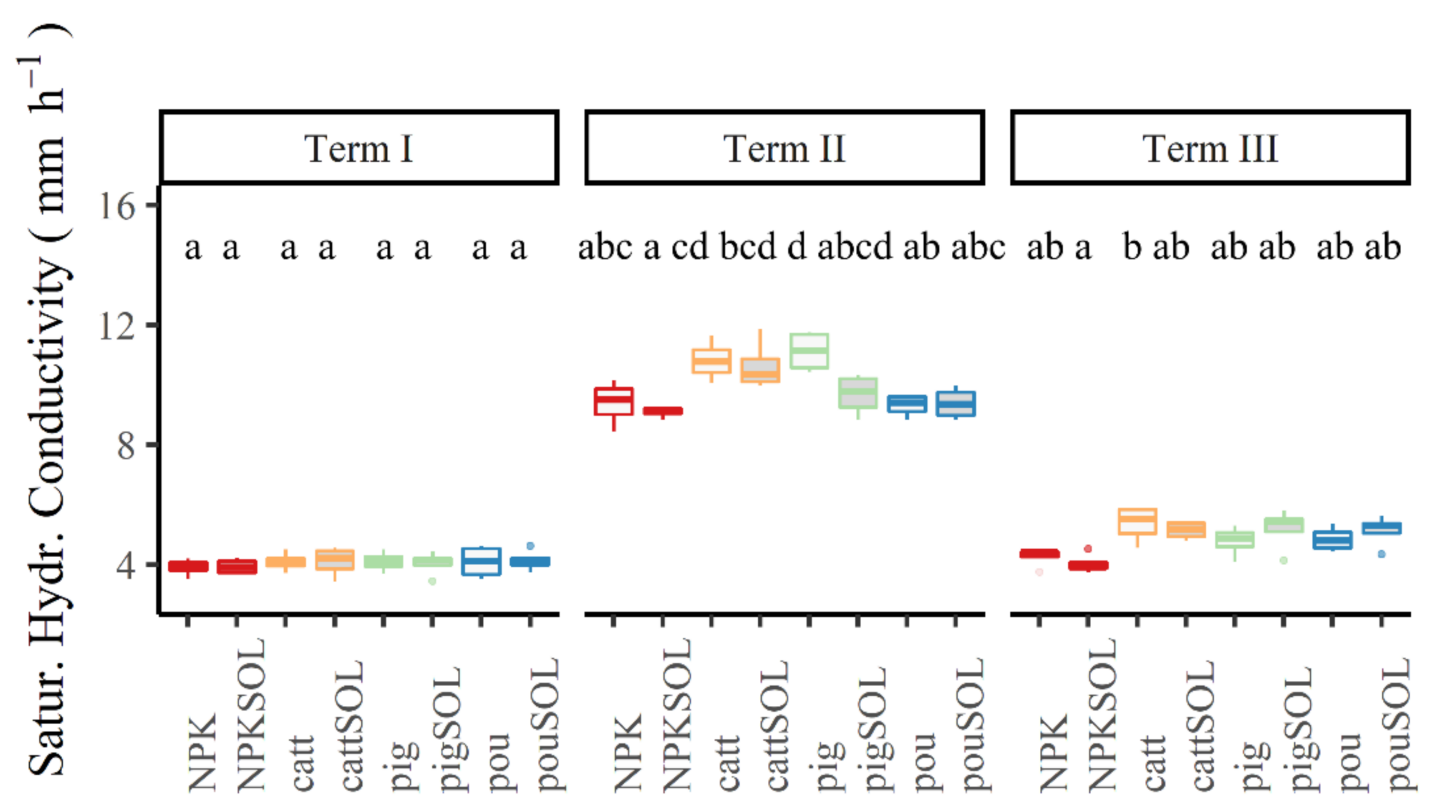

Figure 3. Saturated hydraulic conductivity within variants during the three investigated seasons. Error bars indicate the standard deviation, and letters represent multiple comparisons according to the results of Tukey's HSD test.

\subsection{Vegetation Indices}

The NDVI, NDWI, and LAI were generated from as many cloud-free Sentinel-2 images as there were available. These indexes introduced the spatial information of crop status in terms of (a) plant health, (b) water content, and (c) leaf area. Figure 4 depicts trends of the chosen indices through investigated cropping seasons that brought an overview information of the crop development, mostly in terms of the time effect of the used treatments.

ANOVA with the random effect of the date was performed to examine the potential diverse impact of treatments on both soil and crop status. Multiple comparisons are given in Table 4, where the gray highlighted lines represent the results of paired variants. These comparisons were supposed to answer the question of whether the NeOsol addition to the usual treatment was beneficial in terms of crop growth. It can be seen that no significant difference was found in any of these paired groups in any season. Some significant differences were observable for other variants. Those, however, appeared mostly between the control variant (NPK and NPKSOL) and variants enriched by organic matter of any kind. Hence, the effect of $\mathrm{NeOsol}$ addition was not verified when evaluating crop status. When focusing on the latest season (2020), the LAI was probably the most sensitive indicator, since it was also able to detect the differences among various manure types (e.g., poultry manure performed better than cattle). 
Table 4. Multiple comparisons of crop status derived from three selected vegetation indices based on Tukey's HSD test. Paired variants (with/without NeOsol) are highlighted by gray color, and statistical significance levels are in bold as follows: $p<0.05\left({ }^{*}\right), p<0.01\left(^{* *}\right)$, and $p<0.001\left(^{* * *}\right)$.

\begin{tabular}{|c|c|c|c|c|c|c|c|c|c|c|c|c|}
\hline & NDVI & & & & NDWI & & & & LAI & & & \\
\hline & 2017 & 2018 & 2019 & 2020 & 2017 & 2018 & 2019 & 2020 & 2017 & 2018 & 2019 & 2020 \\
\hline NPK-NPKSOL & -0.0049 & -0.0037 & 0.0007 & -0.0040 & -0.0074 & 0.0062 & -0.0018 & -0.0069 & -0.1032 & 0.1544 & -0.0075 & -0.0427 \\
\hline NPK-catt & -0.0126 & -0.0159 & -0.0125 & $-0.0328 * * *$ & -0.0225 & -0.0225 & $-0.0243 * *$ & $-0.0493 * * *$ & -0.2705 & -0.0196 & -0.1401 & $-0.3302 * * *$ \\
\hline NPK-cattSOL & -0.0121 & -0.0107 & -0.0087 & $-0.0256 * * *$ & -0.0218 & -0.0144 & -0.0195 & $-0.0385 * * *$ & -0.2154 & 0.1198 & -0.1054 & $-0.2519 * *$ \\
\hline NPK-pigSOL & $-0.0182 *$ & $-0.0410 * *$ & $-0.0191 * *$ & $-0.0384 * * *$ & $-0.0333 *$ & -0.0338 & $-0.0284 * *$ & $-0.0554 * * *$ & -0.3051 & -0.9308 & $-0.3241 * *$ & $-0.5624 * * *$ \\
\hline NPK-pou & -0.0125 & $-0.0403 * *$ & $-0.0226 * * *$ & $-0.0384 * * *$ & $-0.0291 *$ & -0.0206 & $-0.0290 * *$ & $-0.0545 * * *$ & -0.1564 & -0.8391 & $-0.3627 * * *$ & $-0.5481 * * *$ \\
\hline NPK-pouSOL & -0.0129 & -0.0316 & $-0.0188^{* *}$ & $-0.0354 * * *$ & $-0.0289 *$ & -0.0215 & $-0.0249 * *$ & $-0.0519 * * *$ & -0.1757 & -0.6348 & $-0.3284^{* *}$ & $-0.5207^{* * *}$ \\
\hline NPKSOL-catt & -0.0077 & -0.0123 & -0.0132 & $-0.0288^{* * *}$ & -0.0150 & -0.0287 & $-0.0225 *$ & $-0.0425 * * *$ & -0.1673 & -0.1739 & -0.1325 & $-0.2874 * * *$ \\
\hline NPKSOL-pig & -0.0059 & $-0.0331 *$ & $-0.0180 *$ & $-0.0312 * * *$ & -0.0158 & -0.0374 * & $-0.0273^{* *}$ & $-0.0460^{* * *}$ & -0.1508 & -0.6198 & -0.2256 & $-0.4401^{* * *}$ \\
\hline NPKSOL-pigSOL & -0.0133 & $-0.0373 *$ & $-0.0198 * *$ & $-0.0343 * * *$ & -0.0259 & $-0.0400 *$ & $-0.0266 * *$ & $-0.0485 * * *$ & -0.2019 & $-1.0852 *$ & $-0.3165 * *$ & $-0.5197 * * *$ \\
\hline NPKSOL-pou & -0.0076 & -0.0366 * & $-0.0233^{* * *}$ & $-0.0344^{* * *}$ & -0.0217 & -0.0268 & $-0.0273 * *$ & $-0.0476^{* * *}$ & -0.0532 & -0.9935 * & $-0.3551 * *$ & $-0.5054^{* * *}$ \\
\hline NPKSOL-pouSOL & -0.0081 & -0.0279 & $-0.0195^{* *}$ & $-0.0314 * * *$ & -0.0214 & -0.0277 & $-0.0231 *$ & $-0.0450 * * *$ & -0.0725 & -0.7892 & $-0.3209^{* *}$ & $-0.4780^{* * *}$ \\
\hline catt-cattSOL & 0.0005 & 0.0053 & 0.0038 & 0.0072 & 0.0006 & 0.0081 & 0.0048 & 0.0109 & 0.0551 & 0.1393 & 0.0347 & 0.0783 \\
\hline catt-pig & 0.0018 & -0.0209 & -0.0048 & -0.0024 & -0.0007 & -0.0087 & -0.0048 & -0.0035 & 0.0165 & -0.4458 & -0.0931 & -0.1526 \\
\hline catt-pigSOL & -0.0056 & -0.0251 & -0.0066 & -0.0056 & -0.0108 & -0.0113 & -0.0040 & -0.0060 & -0.0346 & -0.9113 & -0.1840 & $-0.2323 * *$ \\
\hline catt-pou & 0.0001 & -0.0243 & -0.0101 & -0.0056 & -0.0067 & 0.0019 & -0.0047 & -0.0051 & 0.1142 & -0.8196 & -0.2226 & $-0.2179 *$ \\
\hline catt-pouSOL & -0.0003 & -0.0156 & -0.0063 & -0.0027 & -0.0064 & 0.0010 & -0.0006 & -0.0026 & 0.0949 & -0.6153 & -0.1884 & -0.1905 \\
\hline cattSOL-pig & 0.0013 & -0.0261 & -0.0086 & -0.0096 & -0.0014 & -0.0168 & -0.0096 & -0.0144 & -0.0386 & -0.5851 & -0.1278 & $-0.2309 * *$ \\
\hline cattSOL-pouSOL & -0.0009 & -0.0209 & -0.0101 & -0.0098 & -0.0070 & -0.0071 & -0.0054 & -0.0134 & 0.0397 & -0.7546 & -0.2231 & $-0.2688^{* *}$ \\
\hline pig-pigSOL & -0.0074 & -0.0042 & -0.0017 & -0.0031 & -0.0101 & -0.0026 & 0.0008 & -0.0025 & -0.0511 & -0.4655 & -0.0909 & -0.0796 \\
\hline pig-pou & -0.0017 & -0.0034 & -0.0053 & -0.0032 & -0.0059 & 0.0106 & 0.0001 & -0.0016 & 0.0977 & -0.3738 & -0.1295 & -0.0653 \\
\hline pig-pouSOL & -0.0022 & 0.0053 & -0.0015 & -0.0002 & -0.0057 & 0.0097 & 0.0042 & 0.0010 & 0.0783 & -0.1695 & -0.0953 & -0.0379 \\
\hline pigSOL-pou & 0.0057 & 0.0007 & -0.0035 & 0.0000 & 0.0042 & 0.0132 & -0.0007 & 0.0009 & 0.1488 & 0.0917 & -0.0386 & 0.0143 \\
\hline pigSOL-pouSOL & 0.0052 & 0.0094 & 0.0002 & 0.0029 & 0.0044 & 0.0123 & 0.0035 & 0.0035 & 0.1295 & 0.2960 & -0.0044 & 0.0417 \\
\hline pou-pouSOL & -0.0005 & 0.0087 & 0.0038 & 0.0029 & 0.0003 & -0.0009 & 0.0042 & 0.0026 & -0.0193 & 0.2043 & 0.0342 & 0.0274 \\
\hline
\end{tabular}


- NPK $*$ catt $=$ pig $*$ pou

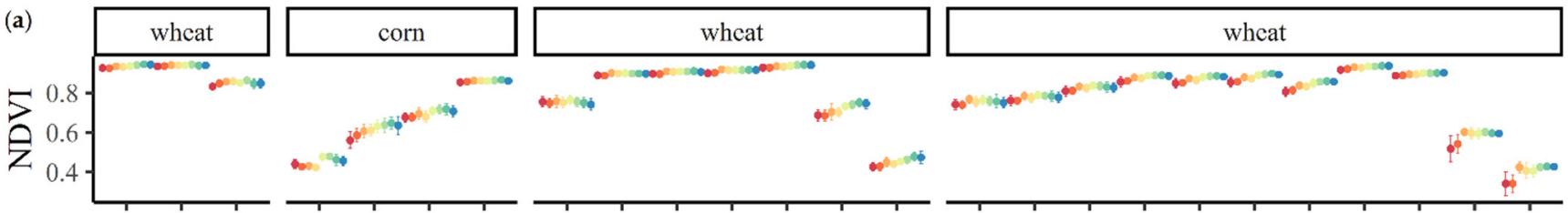

(b)

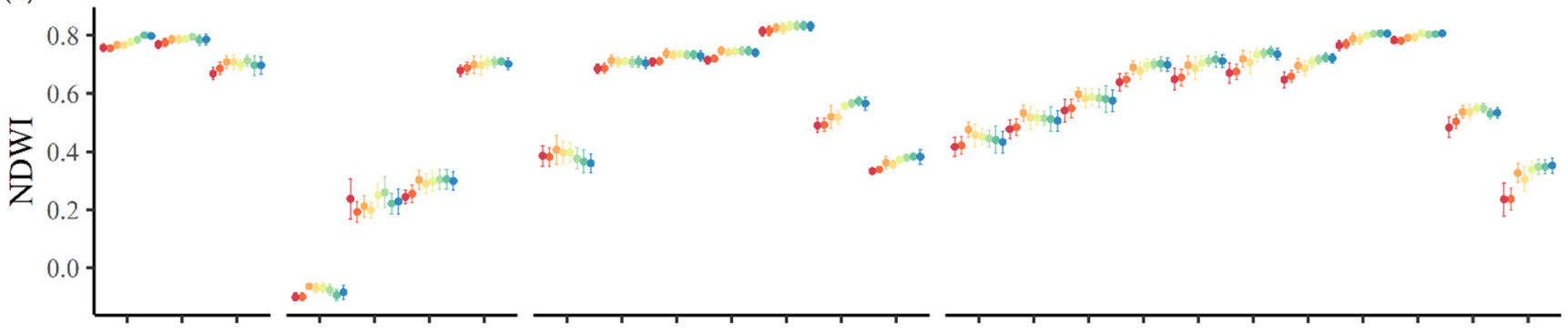

(c)

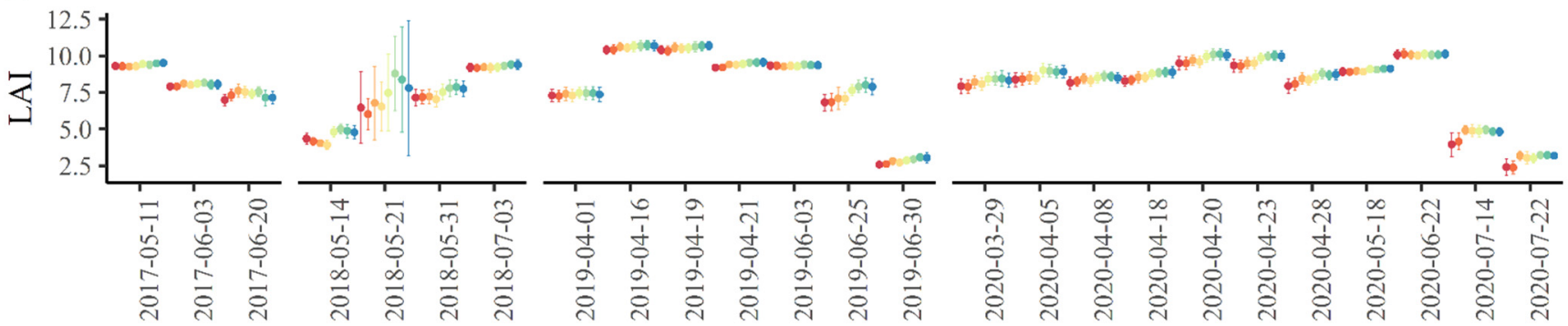

Figure 4. Crop status in terms of (a) crop health and biomass represented by the Normalized Difference Vegetation Index (NDVI), (b) crop water content status represented by the Normalized Difference Water Index (NDWI), and (c) canopy leaf area represented by the Leaf Area Index (LAI). Indices were derived from Sentinel-2 satellite imagery during the 2017-2020 cropping seasons. Error bars represent the standard deviation of index (pixel) values within each investigated small plot.

\subsection{Yield}

Table 5 presents the results of crop yields. When primarily focusing on variations between paired variants differing only in NeOsol content, higher yields were clearly obtained by the variants enriched with NeOsol, particularly at Terms II and III. This was also the case for cattle and pig manure in all three terms. Regarding poultry manure, the effect was observed at Terms II and III. NeOsol addition also had a beneficial effect on yield in the case of the NPK variant at Terms II and III. When applying the factorial (term; manure type; NeOsol treatment) analysis of variance, the overall difference between variants treated with $\mathrm{NeOsol}$ and the untreated variants was found to be significant. At the last term, the difference was most profoundly demonstrated. The pig and poultry manure types showed significantly higher yields than the variants where no manure was applied. When assessing the results separately within individual terms, the corn yields of the pigSOL and pou variants were significantly higher than most of the others. Term II did not demonstrate any significant differences among winter wheat yields. At Term III, however, almost all the variants reached significantly higher yields than the NPK variant. 
Table 5. Descriptive statistics of yield (Mean \pm Std. Dev.) during the terms of the field experiment and the results of one-way ANOVA through Tukey's HSD test.

\begin{tabular}{cccc}
\hline Variant. & $\begin{array}{c}\text { Term } \mathbf{I} \\
\text { Corn }\left(\mathbf{t ~ h a}^{-\mathbf{1}}\right)\end{array}$ & $\begin{array}{c}\text { Term II } \\
\text { Winter Wheat }\left(\mathbf{t ~ h a}^{-\mathbf{1}}\right)\end{array}$ & $\begin{array}{c}\text { Term III } \\
\text { Winter Wheat }\left(\mathbf{t} \mathbf{~ h a}^{-\mathbf{1}}\right)\end{array}$ \\
\hline NPK & $32.9 \pm 0.7(\mathrm{a})$ & $7.71 \pm 0.35(\mathrm{a})$ & $7.36 \pm 0.33(\mathrm{a})$ \\
NPKSOL & $32.3 \pm 0.8(\mathrm{a})$ & $7.95 \pm 0.33(\mathrm{a})$ & $8.11 \pm 0.32(\mathrm{~b})$ \\
catt & $32.5 \pm 0.7(\mathrm{a})$ & $8.43 \pm 0.42(\mathrm{a})$ & $7.93 \pm 0.21(\mathrm{ab})$ \\
cattSOL & $33.1 \pm 0.7(\mathrm{ab})$ & $8.48 \pm 0.42(\mathrm{a})$ & $8.29 \pm 0.40(\mathrm{~b})$ \\
pig & $32.1 \pm 1.0(\mathrm{a})$ & $7.71 \pm 0.36(\mathrm{a})$ & $8.11 \pm 0.18(\mathrm{~b})$ \\
pigSOL & $35.7 \pm 0.6(\mathrm{c})$ & $8.10 \pm 0.46(\mathrm{a})$ & $8.38 \pm 0.22(\mathrm{~b})$ \\
pou & $34.8 \pm 0.8(\mathrm{bc})$ & $7.62 \pm 0.30(\mathrm{a})$ & $8.11 \pm 0.19(\mathrm{~b})$ \\
pouSOL & $32.3 \pm 0.9(\mathrm{a})$ & $7.90 \pm 0.41(\mathrm{a})$ & $8.32 \pm 0.19(\mathrm{~b})$ \\
\hline
\end{tabular}

\section{Discussion}

UD is a commonly used metric for assessing energy demand during soil tillage, since it gives the information about the energy necessary for tillage tools to loosen the topsoil. Soil tillage is the most energy-demanding operation in the crop production process, and a decrease in fossil fuel usage should be the crucial goal in sustainable crop production [32]. UD is highly influenced by soil moisture content, tillage depth, and operation speed [33]. The study of Liang et al. [34] concluded that the application of manure has reduced the energy demand of tillage. In case of our study, the results regarding pig and poultry manure confirm Liang's results, though less so for cattle manure. The results regarding the pig manure are in line with the work of Mclaughlin et al. [35], who reported that repeated applications of manure are reflected in reduced tillage energy. The results concerning cow manure with $\mathrm{NeOsol}$ are, however, not in line with the work of Žemličková and Šařec [36], who reported an increase in unit draft at one year after application. Urbanovičová et al. [15] described a decrease in tension force at ploughing by $5.71 \%$ after three applications of $\mathrm{NeOsol} \mathrm{compared} \mathrm{to} \mathrm{an} \mathrm{untreated} \mathrm{plot.} \mathrm{All} \mathrm{three} \mathrm{applications} \mathrm{were} \mathrm{carried} \mathrm{out} \mathrm{within} \mathrm{the}$ years 2015-2016, and the draft of a plough was only measured at the end of the experiment. Tuba et al. [37] also reported a considerable decrease in plough draft after NeOsol treatment in their three-year experiment. In this study, we only observed a significant decrease in UD by $2.9 \%$ after six years of $\mathrm{NeOsol}$ treatment.

$\mathrm{BD}$ is an important indicator of soil compaction. BD values vary with the time delay from soil tillage. Immediately after tillage, values are lowest and tend to increase during the season due to climatic factors and mechanical load exerted on the soil surface $[38,39]$. According to the USDA [40], the ideal bulk density for optimal plant growth on soils with a clay content of more than $45 \%$ is lower than $1.1 \mathrm{~g} \mathrm{~cm}^{-3}$. In case of this study, this threshold was exceeded for each term. The pigSOL variant achieved better results in comparison to the pure pig manure. Schjonning et al. [41] reported that long-term cattle manure application led to the decline in soil $\mathrm{BD}$, and Hemmat et al. [42] reported that different $\mathrm{BD}$ values were more influenced by the application rate of manure than the manure origin. The results regarding the NPKSOL variant in our study are in line with Urbanovičová et al. [15], who found an increase in BD in the topsoil with NeOsol. The long-term results regarding the pigSOL variant also confirm the results of Šařec and Žemličková [43], who found that the application of NeOsol in combination with pig manure led to an improvement in BD in the topsoil.

SHC is a staple hydrogeological parameter that describes a soil's ability to infiltrate water and distribute it further to the crop root system. Our observations concerning SHC or infiltration rate in general are by and large consistent with past ones [44,45], which have shown improvements in infiltration processes and reductions in surface runoff rates and soil loss for soils with various organic soil treatments from livestock production. Apart from different types of organic matter, some activators have also been examined. Particularly, biochar [46] was found to significantly increase the final infiltration rate and significantly reduce soil loss. However, in our study, $\mathrm{NeOsol}$ did not demonstrate any such effect. 
The major advantage of the utilization of remote sensing data in agriculture is the fact that a canopy can be easily observed in a non-destructive manner with a high temporal resolution ( 5 days for Sentinel-2 at the equator in ideal meteorological conditions). This results in a complex set of data that provides information about crop development during the cropping season. Figure 4 and Table 4 illustrate this kind of information, and even though no significant difference between paired variants has so far been observable, the timeline shows a clear trend. Starting at the 2017 season with almost no difference between treatments, the significance increased over time. In 2020, strong differences between NPK, NPKSOL, and the variants with any manure can be clearly observed in every comparison level by all three indices. NeOsol's contribution to higher chlorophyll content has already been described in several studies $[17,18,20,47]$. It is therefore likely that the desired impact of the management of crop status might be detected in the following seasons, e.g., over a longer time span after NeOsol application.

The NDWI was calculated to gain information regarding crop water content, which was closely related to the SHC soil property. Šindelková, Badalíková, and Kubíková [13] stated that improvements in soil properties using activators leads to preferable utilization of water and nutrient uptake by plants. Nonetheless, though SHC results (Figure 3) demonstrate the only difference between the NPKSOL and the catt variant at Term III, crop water status via the NDWI differed on several more levels. Here again, the major advantage of spatial data is noticeable, as they provide more accurate information than point sampled data.

Sustainable agriculture is necessary to provide careful nutrient management, which is important for increasing soil organic carbon due to improving agricultural productivity and maintaining ecosystem health [48]. One of the possibilities may be the application of manure, which improves soil fertility even in combination with mineral fertilizers [49]. On the other hand, the application of inorganic fertilizers directly leads to higher yields by providing nutrients that encourage crop growth [50]. In both years of the mentioned experiment, the yield of winter wheat grain significantly increased and almost proportionally to the increasing doses of compost. The application of the soil improver on the background of compost further significantly increased the grain yield. However, the soil improver applied in the control treatment, without compost, had an insignificant impact on the wheat yield [24]. Several experiments were conducted to verify the effect of PRP SOL (now NeOsol) on yields with diverse outcomes. The PRP SOL activator proved to be a useful soil additive for calendula growing, as it was found to increase the yield of dry matter of flowerheads [21]. PRP SOL can also replace the inorganic fertilizing of spring barley with phosphorus and potassium without grain yield losses [51]. Another study [52] of a two-year soybean experiment did not show any statistically significant increase in yields when using the SOL activator. Conversely, PRP SOL in combination with urea was found to have a positive effect in terms of increased soybean yield [19]. Our observations have proven the significant effects of $\mathrm{NeOsol}$ on yield, which were intensified after a prolonged application, i.e., at the last term of the experiment.

This experiment verified beneficial effect of the NeOsol activator on crop yield and the unit draft of tillage implements after a prolonged application. In an agricultural practice, this may manifest in higher revenues from crops and lower fuel consumption of soil tillage.

\section{Conclusions}

We carried out a six-year experiment on the biostimulator $\mathrm{NeOsol}$ and three manure types of different origin (cattle, pig, and poultry) that were applied either alone or in a combination in order to assess their influence on soil's physical properties and crop status in real agricultural conditions. The evaluation focused on three terms when manure had been applied beforehand.

Concerning unit draft (UD), the overall influence of NeOsol regardless of time development was not significant. However, though at Term I, variants treated with NeOsol attained higher UD values, the values become significantly lower at Term III (by $2.9 \%$ ). 
This fact suggests the favorable influence of the NeOsol activator on UD over a prolonged period of time. The variants with manure application, particularly pig manure (by 6.5\%) and poultry manure to some extent (by 2.1\%), attained significantly lower UD values than those without treatment. Regarding soil bulk density (BD), NeOsol did not show any significant influence, whereas pig manure (by 6.7\%) and particularly poultry manure (by $10.3 \%$ ) presented significantly lower values compared to the variants without any manure.

No significantly different values of saturated hydraulic conductivity (SHC) could be observed between the variants including those with/without the NeOsol biostimulator over the whole trial period. On the other hand, pig manure (by 12.4\%) and particularly cattle manure (by 15.9\%) application led to significantly decreased SFH values compared to the variants without manure treatment.

NeOsol's effect on several vegetation indices (VI) proved inconclusive as opposed to the variants enriched by the manure of any origin. When assessing yield, however, NeOsol's effect was significant. At the last term of the experiment, the difference in winter wheat yield reached $5.0 \%$. A similar outcome was produced by manure application, where the variants with pig and poultry manure presented $3.8 \%$ and $2.7 \%$ higher average yields, respectively, than the other treatments. At Term III, the difference was significant even for all three manure types, i.e., cattle, pig, and poultry manure surpassed the yields of variants without manure by $4.8 \%, 6.6 \%$, and $6.2 \%$, respectively.

Author Contributions: Conceptualization, V.N. and K.K.; methodology, P.Š.; data analysis, V.N., K.K. and P.Š.; field measurement, V.N., P.Š., P.N. and O.L.; writing-original draft preparation, V.N., P.Š. and K.K.; writing - review and editing, V.N., P.Š. and K.K.; supervision, V.N. All authors have read and agreed to the published version of the manuscript.

Funding: This research was funded by the Technology Agency of the Czech Republic, grant number TH02030169 and by Czech University of Life Sciences, Faculty of Engineering, grant number IGA 2020:31180/1312/3103. This research was also funded by the Ministry of Agriculture of the Czech Republic, Project No. RO0418.

Institutional Review Board Statement: Not applicable.

Informed Consent Statement: Not applicable.

Data Availability Statement: The data presented in this study are available on request from the corresponding author.

Acknowledgments: The authors would like to express their gratitude to the Technology Agency, to the Ministry of Agriculture of the Czech Republic, and to the Czech University of Life Sciences, Faculty of Engineering for providing financial grant support to conduct the research. The main author would also like to thank all colleagues that took part in the research for their support and cooperation.

Conflicts of Interest: The authors declare no conflict of interest.

\section{References}

1. Anderson, R.; Bayer, P.E.; Edwards, D. Climate Change and the Need for Agricultural Adaptation. Curr. Opin. Plant Biol. 2020, 56, 197-202. [CrossRef]

2. Jain, H.K. The Green Revolution History, Impact and Future; Studium Press LLC: Houston, TX, USA, $2010 ;$ ISBN 1933699639.

3. Pham, X.; Stack, M. How Data Analytics Is Transforming Agriculture. Bus Horiz. 2018, 61, 125-133. [CrossRef]

4. Zhai, Z.; Martínez, J.F.; Beltran, V.; Martínez, N.L. Decision Support Systems for Agriculture 4.0: Survey and Challenges. Comput. Electron. Agric. 2020, 170, 105256. [CrossRef]

5. Klerkx, L.; Rose, D. Dealing with the Game-Changing Technologies of Agriculture 4.0: How Do We Manage Diversity and Responsibility in Food System Transition Pathways? Glob. Food Sec. 2020, 24. [CrossRef]

6. Maeder, P.; Fliessbach, A.; Dubois, D.; Gunst, L.; Fried, P.; Niggli, U. Soil Fertility and Biodiversity in Organic Farming. Science 2002, 296, 1694-1697. [CrossRef]

7. Goldberg, N.; Nachshon, U.; Argaman, E.; Ben-Hur, M. Short Term Effects of Livestock Manures on Soil Structure Stability, Runoff and Soil Erosion in Semi-Arid Soils under Simulated Rainfall. Geosciences 2020, 10, 213. [CrossRef]

8. Gilley, J.E.; Risse, L.M.; Eghball, B. Managing Runoff Following Manure Application. J. Soil Water Conserv. 2002, 57, 530-533. 
9. Badalucco, L.; Rao, M.; Colombo, C.; Palumbo, G.; Laudicina, V.A. Reversing Agriculture from Intensive to Sustainable Improves Soil Quality in a Semiarid South Italian Soil. Biol. Fertil Soils 2010, 46, 481-489. [CrossRef]

10. Menšík, L.; Hlisnikovský, L.; Pospíšilová, L.; Kunzová, E. The Effect of Application of Organic Manures and Mineral Fertilizers on the State of Soil Organic Matter and Nutrients in the Long-Term Field Experiment. J. Soils Sediments 2018, 18, 2813-2822. [CrossRef]

11. Food and Agriculture Organizations of the United Nations Food and Agriculture Data. Available online: http://www.fao.org/ faostat (accessed on 22 October 2021).

12. Spychalski, W.; Sulewska, H.; Ratajczak, K.; Kaczmarek, T. Composition of Soil Solution after 10 Years of PRP SOL Fertilization Based on the Selected Chemical Properties. J. Res. Appl. Agric. Eng. 2017, 62, 139-143.

13. Šindelková, I.; Badalíková, B.; Kubíková, Z. The Soil Biostimulant Usage Effect on Soil Properties in Dry Area. In Proceedings of the International Multidisciplinary Scientific GeoConference Surveying Geology and Mining Ecology Management, SGEM, Albena, Bulgaria, 28 June-7 July 2019; Volume 19, pp. 561-568.

14. Szúcs, L.; Tuba, G.; Zsembeli, J. Effect of PRPSOL Soil Conditioner on the Physical Status of the Soil in Conventional and Reduced Tillage Systems. Acta Agrar. Debreceniensis 2014, 55, 109-113. [CrossRef]

15. Urbanovičová, O.; Krištof, K.; Findura, P.; Mráz, M.; Jobbágy, J.; Križan, M. The Effect of Soil Conditioner on the Spatial Variability of Soil Environment. Agron. Res. 2018, 16, 2197-2210. [CrossRef]

16. Bielińska, E.J.; Futa, B.; Bik-Mołodzińska, M.; Szewczuk, C.; Sugier, D. The Impact of Fertilizing Agents on the Enzymatic Activity of Soils (Wpływ preparatów użyźniających na aktywność enzymatyczną gleb). J. Res. Appl. Agric. Eng. 2013, 58, 15-19.

17. Borowiak, K.; Niewiadomska, A.; Sulewska, H.; Szymanska, G. Effect of PRP SOL and PRP EBV Nutrition on Yield, Photosynthesis Activity and Soil Microbial Activity of Three Cereal Species. Fresenius Environ. Bull. 2016, 25, 2026-2035.

18. Swędrzyńska, D.; Zielewicz, W.; Swędrzyński, A. Comparison of Soil Bioconditioners and Standard Fertilization in Terms of the Impact on Yield and Vitality of Lolium Perenne and Soil Biological Properties. Open Life Sci. 2019, 14, 666-680. [CrossRef]

19. Jukić, G.; Šunjić, K.; Varnica, I.; Gašo, D.; Labudović, B. Effect of Different Kinds of Fertilizer on Soybean Yield. In Proceedings of the 8th International Scientific/Professional Conference, Agriculture in Nature and Environment Protection, Vukovar, Croatia, 1-3 June 2015; pp. 110-115.

20. Sulewska, H.; Niewiadomska, A.; Majchrzak, L.; Panasiewicz, K. Potatoes Reaction on PRP SOL Fertilisation. J. Res. Appl. Agric. Eng. 2012, 57, 116-121.

21. Ratajczak, K.; Sulewska, H.; Szymańska, G.; Wolna-Maruwka, A.; Faligowska, A. The Effect of Soil Type and Soil Additives on the Selected Growth Parameters and Yield of Flowerheads of Calendula Officinalis L. Herba Polonica 2016, 62, 17-30. [CrossRef]

22. Porro, D.; Pedò, S. Implication of Nutrition on Root Development. In Proceedings of the I International Symposium on Grapevine Roots, Rauscedo, Italy, 16-17 October 2014; pp. 193-200.

23. Krzywy-Gawrońska, E. Enzymatic Activity of Urease and Degydrogenase in Soil Fertilized with GWDA Compost with or without a PRP SOL Addition. Pol. J. Environ. Stud. 2012, 21, 949-955.

24. Krzywy-Gawrońska, E.; Woloszyk, C. Effect of Compost Produced by the GWDA Method and PRP SOL on the Yield of Winter Wheat and Soil Properties. Fertil. Fertil. 2011, 43, 29-38.

25. Klír, J.; Kunzová, E.; Cérmák, P. Frame Methodics of Plant Nutrition and Fertilization (RáMcová Metodika Výživy Rostlin a Hnojení), 2nd ed.; Crop Research Institute: Prague, Czech Republic, 2008; ISBN 78-80-87011-61-4.

26. Bagarello, V.; Iovino, M.; Elrick, D. A Simplified Falling-Head Technique for Rapid Determination of Field-Saturated Hydraulic Conductivity. Soil Sci. Soc. Am. J. 2004, 68, 66-73. [CrossRef]

27. Elrick, D.E.; Reynolds, W.D.; Tan, K.A. Hydraulic Conductivity Measurements in the Unsaturated Zone Using Improved Well Analyses. Groundw. Monit. Remediat. 1989, 9, 184-193. [CrossRef]

28. Rouse, R.W.H.; Haas, J.A.W.; Deering, D.W. Monitoring Vegetation Systems in the Great Plains with ERTS. In Proceedings of the Third Earth Resources Technology Satellite-1 Symposium NASA SP-351, Washington, DC, USA, 10-14 December 1973; Section A. Volume 1, pp. 309-317.

29. Gao, B.C. NDWI-A Normalized Difference Water Index for Remote Sensing of Vegetation Liquid Water from Space. Remote Sens. Environ. 1996, 58, 257-266. [CrossRef]

30. Boegh, E.; Soegaard, H.; Broge, N.; Hasager, C.B.; Jensen, N.O.; Schelde, K.; Thomsen, A. Airborne Multispectral Data for Quantifying Leaf Area Index, Nitrogen Concentration, and Photosynthetic Efficiency in Agriculture. Remote Sens. Environ. 2002, 81, 179-193. [CrossRef]

31. RStudio Team RStudio: Integrated Deveopment for R; R Foundation: Vienna, Austria, 2021.

32. Moitzi, G.; Neugschwandtner, R.W.; Kaul, H.; Wagentristl, H. Energy Efficiency of Winter Wheat in a Long-Term Tillage Experiment under Pannonian Climate Conditions. Eur. J. Agron 2019, 103, 24-31. [CrossRef]

33. Rashidi, M.; Najjarzadeh, I.; Jaberinasab, B.; Emadi, S.M.; Fayyazi, M. Effect of Soil Moisture Content, Tillage Depth and Operation Speed on Draft Force of Moldboard Plow. Middle East J. Sci. Res. 2013, 16, 245-249. [CrossRef]

34. Liang, A.; Mclaughlin, N.B.; Ma, B.L.; Gregorich, E.G.; Morrison, M.J.; Burtt, S.D.; Patterson, B.S.; Evenson, L.I. Changes in Mouldboard Plough Draught and Tractor Fuel Consumption on Continuous Corn after 18 Years of Organic and Inorganic N Amendments. Energy 2013, 52, 89-95. [CrossRef]

35. Mclaughlin, N.B.; Gregorich, E.G.; Dwyer, L.M.; Ma, B.L. Effect of Organic and Inorganic Soil Nitrogen Amendments on Mouldboard Plow Draft. Soil Tillage Res. 2002, 64, 211-219. [CrossRef] 
36. Žemličková, N.; Šařec, P. Influence of Application of Organic Matter and Its Activators on Soil-Tillage Implement Draft on Modal Luvisol. In Proceedings of the 6th International Conference on Trends in Agricultural Engineering, Prague, Czech Republic, 7-9 September 2016; pp. 736-742.

37. Tuba, G.; Kovács, G.; Sinka, L.; Nagy, P.; Rivera-Garcia, A.; Bajusová, Z.; Findura, P.; Zsembeli, J. Effect of Soil Conditioning on Soil Penetration Resistance and Traction Power Demand of Ploughing. Agriculture 2021, 67. [CrossRef]

38. Blanco-canqui, H.; Stone, L.R.; Schlegel, A.J.; Lyon, D.J.; Vigil, M.F.; Mikha, M.M.; Stahlman, P.W.; Rice, C.W. No-till Induced Increase in Organic Carbon Reduces Maximum Bulk Density of Soils. Soil Sci. Soc. Am. J. 2009, 73, 1871-1879. [CrossRef]

39. Nouri, A.; Lee, J.; Yin, X.; Tyler, D.D.; Jagadamma, S.; Arelli, P. Soil Physical Properties and Soybean Yield as Influenced by Long-Term Tillage Systems and Cover Cropping in the Midsouth USA. Sustainability 2018, 10, 4696. [CrossRef]

40. United States Department of Agriculture. Soil Bulk Density/Moisture/Aeration; United States Department of Agriculture: Washington, DC, USA, 2019.

41. Schjønning, P.; Christensen, B.T.; Carstensen, B. Physical and Chemical Properties of a Sandy Loam Receiving Animal Manure, Mineral Fertilizer or No Fertilizer for 90 Years. Eur. J. Soil Sci. 1994, 45, 257-268. [CrossRef]

42. Hemmat, A.; Aghilinategh, N.; Rezainejad, Y.; Sadeghi, M. Long-Term Impacts of Municipal Solid Waste Compost, Sewage Sludge and Farmyard Manure Application on Organic Carbon, Bulk Density and Consistency Limits of a Calcareous Soil in Central Iran. Soil Tillage Res. 2010, 108, 43-50. [CrossRef]

43. Šařec, P.; Žemličková, N. Soil Physical Characteristics and Soil-Tillage Implement Draft Assessment for Different Variants of Soil Amendments. Agron. Res. 2016, 14, 948-958.

44. Boyle, M.; Frankenberger, W.T.; Stolzy, L.H. The Influence of Organic Matter on Soil Aggregation and Water Infiltration. J. Prod. Agric. 1989, 2, 290-299. [CrossRef]

45. Tejada, M.; Gonzalez, J.L. Influence of Organic Amendments on Soil Structure and Soil Loss under Simulated Rain. Soil Tillage Res. 2007, 93, 197-205. [CrossRef]

46. Abrol, V.; Ben-Hur, M.; Verheijen, F.G.A.; Keizer, J.J.; Martins, M.A.S.; Tenaw, H.; Tchehansky, L.; Graber, E.R. Biochar Effects on Soil Water Infiltration and Erosion under Seal Formation Conditions: Rainfall Simulation Experiment. J. Soils Sediments 2016, 16, 2709-2719. [CrossRef]

47. Šařec, P.; Novák, P.; Kumhálová, J. Impact of Activators of Organic Matter on Soil and Crop Stand Properties in Conditions of Very Heavy Soils. In Proceedings of the Engineering for Rural Development, Jelgava, Latvia, 24-26 May 2017; Volume 16, pp. 486-491.

48. Li, T.; Zhang, Y.; Bei, S.; Li, X.; Reinsch, S.; Zhang, H.; Zhang, J. Contrasting Impacts of Manure and Inorganic Fertilizer Applications for Nine Years on Soil Organic Carbon and Its Labile Fractions in Bulk Soil and Soil Aggregates. Catena 2020, 194, 4739. [CrossRef]

49. Voltr, V.; Menšík, L.; Hlisnikovský, L.; Hruška, M.; Pokorný, E.; Pospíšilová, L. The Soil Organic Matter in Connection with Soil Properties and Soil Inputs. Agronomy 2021, 11, 779. [CrossRef]

50. Liang, Q.; Chen, H.; Gong, Y.; Fan, M.; Yang, H.; Lal, R.; Kuzyakov, Y. Effects of 15 Years of Manure and Inorganic Fertilizers on Soil Organic Carbon Fractions in a Wheat-Maize System in the North China Plain. Nutr. Cycl. Agroecosyst. 2012, 92, 21-33. [CrossRef]

51. Sulewska, H.; Koziara, W.; Szymańska, G.; Niewiadomska, A.; Panasiewict, K.; Ratajczak, K. Response of spring barley to prp sol application as a complex of mineral inducer prosess (MIP). Nauka Przyr. Technol. 2016, 10, 1-14. [CrossRef]

52. Kováč, L.; Jakubová, J.; Šariková, D. Effect of Tillage System and Soil Conditioner Application on Soybean (Glycine Max (L.) Merrill.) and Its Crop Management Economic Indicators. Agriculture 2014, 60, 60-69. [CrossRef] 